\title{
PSYCHOGENIC DISTURBANCES IN CHILDHOOD AND THEIR TREATMENT *
}

\author{
AUGUST STRAUCH \\ Attending Physician at the Cook County Hospital, Children's Department; \\ Instructor in Pediatrics, Rush Medical College; Attending \\ Physician at the Central Free Dispensary \\ CHICAGo
}

Psychogenic diseases play an important rôle in childhood; they are at this period of life much more frequent and their nature is more easily demonstrated than in the adult; they are to a high degree subject to the influence of suggestion therapy and therefore possessed of a paramount importance in the practice of the pediatrician. The necessity of the recognition and appropriate valuation of the psychic elements in the complex of clinical syndromes cannot be emphasized enough.

\section{DEFINITION}

We understand by psychogenic diseases those disorders that emanate and originate from psychic processes, namely, from conscious, subconscious or unconscious ideas, associations, conclusions and impressions with or without accompanying emotions of the affected child. Though many of such disturbances are of hysterical nature, we must be cautious not to identify hysteria with the much broader term of psychogeny. Pain, fear, anxiety and worry, for instance, accompany in the adult perhaps every important somatic disease and lend a peculiar color to the clinical picture; their effects are closely interwoven with the purely organic symptoms through mutual interaction.

In the human mind there is a continuous current of mental processes, of associations, thoughts, ideas and conclusions and emotions, which to a great extent are underneath the surface of the clear consciousness, but which nevertheless leave residual imprints on the central nervous system, not always merely temporarily, but also of some duration and permanence in the form of subconscious or submerged memories and "facilitations." It was the merit of Freud and his school by his analytic methods to have brought the obscure, often deeply buried psychic elements and their intricate relation to somatic disturbances of neurotic character into the compass of scientific research and put them into a clearer perspective and better appreciation by the profession.

\footnotetext{
* Submitted for publication June 22, 1918.
} 
The psychogenic disturbances that are the subject of discussion in this paper may manifest themselves in the sphere of almost any organ, and the aspects of the symptoms are numerous and various. There is scarcely an organ that may not display nervous disorders of the nature of psychogenic reflex processes. They embrace the sensory, secretory and voluntary motor functions as well as those of the smooth muscles that are not directly subject to the will, as those of the gastro-intestinal tract and of the heart.

The psychomechanism, the methods of operation of the provocative occasions and agencies, and the sources of the disorders are of various nature. The latter may be due to imitation and psychic contagion, that is, have their cause in the "suggestion" or reflex receptibility which is a cardinal attribute of psychic life.

The special proneness of children to imitation, their great susceptibility to impressions, their impressionability on account of the immaturity, instability and undevelopment of character, the credulity, vivid imagination, belief in authorities and lack of logical criticism convert example, in their case, into a mighty, almost magic force, both in the psycho-physiologic as well as the pathologic direction.

\section{IMPORTANCE OF EXAMPLE}

In the presence of these peculiarities of the psychic life and on account of its tendency to discharge physical reactions on impressions, the environment or milieu of the child is possessed of momentous import. Therefore, no wonder that a disease, observed in another person, may be mirrored in the psyche and give rise to similar morbid symptoms in children. Particularly will a neurotic, hysterical person render others in contact with him, likewise nervous in the course of time, and the latter will often acquire and appropriate, as it were, certain nervous disorders and habits.

The danger of forming and stabilizing such nervous disorders, induced by the imitativeness and suggestion is, of course, with the child greater than with the adult.

We also frequently make the observation, that children affected with minor ailments will in different environments and surrounded by different persons present great variations in the clinical picture aside from the uniformity of the otherwise, of course, identical diseases, and act differently. Factors not lying within the nature of the pathologic processes themselves, but those of entirely extraneous characters, namely, the influences of the change of milieu, will call forth a change of the symptom complex in its nonobligatory, not organically caused, features; the impressionable plastic psyche of the 
child being affected by the transformative circumstances as clay or wax is shaped under the hand of the modeling artist.

The great historical examples of prodigious psychic epidemics, such as the children's migrations and crusades, the dancing manias, great choreas (St. Vitus' dance), etc., demonstrated the sweeping extent and overwhelming intensity of the suggestion, the power of example and the force of a "contagion idea" as Hecker, a physician, has depicted it with the pen of a historically and psychologically well trained writer.

Also the well known psychic school epidemics of our times, that are recorded in medical literature, give testimony to the great forces dormant in the human mind. For example, we cite the epidemiclike occurrences among many school children of the same classes of tremor, singultus, choreatic movements, disturbances of handwriting, enuresis nocturna, sleeplike states and other peculiar phenomena of the so-called imitation or induction diseases.

For the individual physician more important are the sporadic, isolated cases of psychogenic disturbances of imitative origin. They represent a great variety, they are protean and may affect the nervous system, the psychic sphere and the vegetative functions. As I have dwelt on this feature in a former essay, I may here only summarize, that in children in very numerous instances motor, sensory and visceral disturbances, such as for instance, attacks of limping, tremor of paralysis agitans with more or less exactness of the crude clinical picture, facial and other tics convulsifs, peculiar dyspneas or types of respiration, backache or pain in the chest, in the limbs, in the side or the abdomen, heart palpitations, vomiting, etc., could be traced to no other etiologic factor than to the suggestive influence of the example of their parents, most often the mother, who would complain day by day of their own ailments and pains, imaginary or real, in the presence of their children. The nervous parents through their conduct awake in the child corresponding ideas and impressions and guide its imagination in a certain pathologic direction. Such parents also by their anomalies of character in the sphere of emotion and volition are bound to be of immense educational detriment to their children, aggravating the effect of an hereditary neuropathic constitution by the influence of a morbid environment, the neuropathic milieu.

\section{AUTOSUGGESTION}

But perhaps more than the ailments of others do the child's own diseases influence its psyche. The subjective symptoms of an originally organic disease, as a rule painful or involving the motor function, will be aggravated or prolonged psychogenically. For instance, after 
a catarrhal laryngitis hysterical aphonia may follow; or after tonsillitis, that had kept the patient bedridden, abasia and astasia; or blepharoclonus may remain after the subsidence of acute conjunctivitis or the removal of a foreign body.

Pain, after the complete cure of its organic basis, will become fixed as psychalgia, as douleur d'habitude (Brissaud's), as habit pain; the latter will be, so to speak, the reverberation of the previously actual pain that accompanied some organic disease. Such disturbance represents a condition brought about by auto-imitation of the original disease ; it is the psychogenic residue, "the declaration of permanence" (Bruns) of the subjective symptom of the previous organic disease.

After the disappearance of acute rheumatic polyarthritis, a psychogenic residual pain may persist for a long time and may even be of a very violent nature; these arthralgias may be so intense as to forbid the slightest touch while the child is aware of it, but will disappear entirely if the attention is diverted or in the sleep, so that the child will lie in any position on the affected part.

As classic an example as one could wish to demonstrate this condition is described in the following case:

O. A., a boy aged 5 years, had the following history: Three months ago he became ill with pains in various joints; the left knee particularly was swollen and reddened for awhile; it remained painful permanently. Two months later pains in the right knee, in the ankles and shoulder joints supervened. He had been three months bedridden, when he was admitted to the Cook County Hospital. The boy, when seen by me for the first time, manifested extreme pain on the slightest touch or attempt at passive movements of both hip and knee joints; they were contracted and held in moderate flexion. The feet were slightly painful to pressure. Swelling was not present anywhere. During sleep the contractures, however, disappeared and time and again the boy was found lying in any position of the affected limbs. There was also free passive mobility, if ${ }^{*}$ the child's attention was sufficiently diverted by various tricks. It was indeed a classic example of the psychogenic character of residual, though very vehement pain. After a few days the pain had disappeared completely, but the boy, while rather freely using his legs in bed where he liked to play cheerfully, was entirely unable to stand or walk, manifesting complete astasia and abasia. This astasia and abasia proved rather refractory, perhaps as a result of too much attention and interest shown to him in frequent clinical demonstrations. After about four weeks he rather unexpectedly was found standing up in his bed and climbing over the railing into his neighbor's with remarkable skill, but he was still unable to stand or walk on the floor. Then, for therapeutic reasons his legs were submerged in cold baths twice a day and within three days the control of his legs was restored.

Other patients manifest painful sensations or motor disturbances, as contractures and pseudoparalysis that persist obstinately subsequent to a perhaps insignificant trauma. Two instances that could be multiplied may suffice to exemplify the statement.

The 8-year-old son of an artist after a fall on his right shoulder during play suffered from vehement pain and stiffness of the joint for several days, when 
on examination no lesion could be found. The roentgen-ray examination revealed no lesion. The free passive mobility of the joint when his attention was distracted, and the rather sudden disappearance of pain and contracture after a merely suggestive treatment proved clearly the psychogenic character of this residual disturbance.

M. S., a girl, aged 12 , three months ago when playing, fell forward on the pebbly ground in front of the school. Two days later dull pain in abdomen and headache of a shooting character appeared and has persisted in the form of daily attacks since then. The abdominal pain appeared independent of the meals and the headache occurred every morning and evening, continuing for about one hour; they were brought on or aggravated especially by excitement. There were no objective signs of any injury, but painfulness of the lateral and lower parts of the abdomen on pressure was present. A verbal suggestion emphasizing a complete cure in conjunction with abdominal massage on the spot, brought about the immediate disappearance of the pressure pain. A few drops of tincture of valerian were ordered daily. The headaches and pains in the abdomen never returned.

To show what queer pranks autosuggestion may play on a child, the following case exhibiting a component of phobia may be here reported.

An intelligent boy aged 7 had short but frequent attacks of a feeling of constriction in his throat and inability "to swallow the saliva," causing him "fear of choking." A swallow of water would forthwith relieve the distressing symptom. These attacks by their frequency caused him so much anxiety, that finally he was afraid to go where he would not be able to get water if in need. When outdoors he chose streets or places where he would find a well or pump nearby. On one occasion a more severe attack seized him suddenly in a long street, so he had to hurry to a well; drinking gave immediate relief; but as soon as he had left the well, another attack compelled him to return forthwith; this happened several times in close succession; it was only with apprehensive hesitation, that he ultimately went home. The attacks continued over one week. The boy was otherwise perfectly healthy.

The only explanation I could find of this peculiar disturbance manifested in this boy was perhaps either the possibility of a previous tonsillitis or more likely in combination with the fact, that the boy's phantasy had been much aroused by stories about "choking and impossibility of swallowing" in a case of hydrophobia that had occurred in the town.

The auto-imitation of a previous organic disease, the fixation of a symptom in the psyche, indeed often is directly cultivated and fostered by the overanxiety, morbid solicitude, apprehension, overindulgence and imprudence of some parents. They may by asking the child over and over again after this or that symptom keep the latter alive in the mind of the sick child, or they may yield to every desire and wish, however foolish, of the sick child out of excessive sympathy, and multiply their manifestations of parental care, so that there seems to the child to accrue more advantage from being sick than from being healthy.

This fact holds also true of the so-called oneirogenic (dream- 
produced) disturbances of sleep; as for instance, of somnambulism. As is well known, nervous, especially hysteric children, may occasionally leave their bed due to restless sleep, vivid dreams or fears. If the parents show themselves unconcerned, as a rule the attacks will rapidly disappear spontaneously. However, if much concern is shown and apprehension expressed in the presence of the child, in a number of instances rising from bed and sleep-walking will become more frequent and the morbid tendency aggravated. By ignoring the condition and removing the child from his obnoxious home environment, these procedures, as a rule, soon correct the sleep disturbance, proving by the influence of suggestion its psychogenic nature.

\section{COMPLICATING FACTOR}

Not only may the psychogenic factor assert itself in prolongation of pain after the subsidence of the organic cause, but - as passingly said before-it may also during the organic stage of a disease by aggravation exaggerate the clinical manifestations, or add to the organic complex another complicating symptom which may be recognized as neurotic by the prompt effect of psychic treatment, as will be discussed later in extenso.

The following case will exemplify such an element of psychogenic complication of rheumatic chorea minor.

M. S., a Jewish boy, when admitted to the Cook County Hospital, manifested the symptoms of chorea minor of moderate degree. This was the third recurrence within two years. Lately, according to the history of the case, attacks of violent tremor of both upper extremities had supervened; they continued as long as two hours without cessation, and occurred on some days several times, particularly starting under the influence of excitement and anger. This "trembling" consisted of very rapid pronatory and supinatory rotations of both forearms, the extremities being held spastically extended in the eibow joints, and directed downward. This "trembling" evidently not belonging to chorea minor, never appeared in the hospital and thereby documented its accessory character. The analysis of the etiology made it appear as very probable that the tremor had developed originally from the ordinary tremor that accompanies the effect of anger and wrath.

It is probable that in childhood all psychogenic disturbances originate in some actuality, either in a real organic somatic disease, or in psychic traumas, especially in impressions and experiences that react through the reflex of imitation, or in physical traumas with psychic by-effects. It is not only the severe acute psychic traumatism, that as a provocative factor of neurotic disturbances comes into consideration, but often also the small, apparently insignificant, not dramatic psychic insults, that, if repeated, may have and do exert a cumulative effect. Thus, particularly in the school age, injustices on the part of teacher or schoolmates, disappointments of expectations, frustrated 
ambitions, excessive aspirations overstimulated by the parents, anxieties, fear of examinations, etc., may act as slight but continuous injuries on the sensitive psyche especially of predisposed, angiasthenic, vasoneurotic and impressionable individuals. They may give rise to various morbid manifestations as, for example, heart palpitations, precordial pain, vertigo, etc. Exciting scenes of an unhappy home life act in the same way.

REFLEX INFLUENCES

Many phenomena explained as due to auto-imitation and classified among the manifestations of monosymptomatic hysteria have to be considered as nothing else but "pathologic conditional reflexes," the definition of which Ibrahim has circumscribed, introducing it into our clinical terminology, in his exposé, following Pawlow's doctrine.

A typical example, representative of the conditional reflex of pathologic character is illustrated by the so-called pertussis tic, the "tic coqueluchoide" of Lesage and Collin. As generally known, especially neurotic children, suffering from whooping cough, will for an unduly long period, even for months, continue to have attacks of spasmodic cough; this with the exception of its nonproductiveness of sputum, will mimic the typical pertussis. The children, in a number of instances, may call forth these attacks voluntarily, in order to impress their anxious, apprehensive environment and enforce their capricious will. In other instances, the cough due to acute bronchitis or pharyngitis, if acquired weeks or months after pertussis, may likewise copy its type. Striking therapeutic results are to be obtained at this stage within a few days or even at once by the application of methods that act merely through suggestion and are so successfully employed in hysteria of childhood, as by intentional neglect, brusque commands, energetic orders to suppress the cough, if necessary with emphatic threat of punishment or other educational means. This fact characterizes the nature of the disturbance as an acquired "pathologic conditional reflex" (Ibrahim). The cough impulse constitutes the stimulus for the conditional, semi-voluntary reflex. The children need only produce a few cough impulses either purposely or impelled by broncho-catarrhal or pharyngeal irritation, in order to have started the entire mechanism. The rapid cessation of the attacks, once the child has succeeded in suppressing them a few times under the influence of therapy or by avoidance of their provocations, indeed is in keeping with the extinction of a conditional reflex in the animal experiments of Pawlow and his pupils, or in the experiments of Krasnogorski in children. The fundamental investigations and achievements of these authors, indeed, have thrown a bridge into a new field of fruitful and promising scientific research. 
The conception of an acquired pathologic conditional reflex finds its ready application in "respiratory affect-convulsions," or rage spasm, the apnea in anger-paroxysms (Wegbleiben) of neurotic children. By suddenly springing a surprise, by diversion of the child's attention, by threats or a slight slap, such psychogenic paroxysms can be suppressed in the very start, as a conditional reflex in the animal experiment will be inhibited by the introduction of a new stimulus.

Also the not infrequent nervous vomiting of children in the morning before or on the way to school, may be traced to a psychogenic origin, perhaps under the cooperative, auxiliary influence of emotions, the psychic reflex act of vomiting being firmly anchored to the idea of going to school. In educating babies to defecate or urinate at a given regular time by bringing them on the chamber, we intentionally create a normal conditional reflex, the automatic act of defecation or urination becoming psychically anchored to this newly introduced stimulus. In many adults various sensory impressions, as, for instance, hearing water run, will facilitate the act of micturition, this acoustic stimulus, once established, serving here as an acquired conditional reflex stimulus.

In a boy, aged 5 years, for one and one-half years free bowel movements were obtained only every other day by a small enema; without the latter he obstinately refused to defecate. For him the enema evidently represented an acquired but apparently indispensable psychic stimulus more than anything else. The enemas for therapeutic reasons were completely discontinued, and after a few days of constipation the boy became convinced of his ability of spontaneous defecation, thus acquiring the normal habit.

The following neurotic disturbance, observed by me lately in the dispensary of the Rush Medical College may be cited.

A boy, aged 9 years, fond of school work, has suffered for several years from abdominal pain, that continues regularly from about 10 to 12 noon and from 2 to about $3: 15$ p. m. A close examination revealed, in addition to a slight diastasis of the recti muscles, rigidity of the abdominal walls and pain over the entire abdomen on pressure. The fact that the pain never appeared on Saturdays and Sundays or during the school vacations revealed the merely neurotic character of the disutrbance; its rapid improvement after a single application of the faradic current, and its complete disappearance within two weeks confirmed the diagnosis. The boy received a few drops of tincture of valerian daily.

\section{ONEIROGENIC DISTURBANCES AND PAIN HALLUCINATIONS}

It is a not sufficiently noted but very noteworthy fact, that also oneirogenic disturbances, that is, those due to the operation of dreamideas or dreamlike states are amenable to the salutary influence of suggestive treatment, applied during the waking state. Not only pavor 
nocturnus, somnambulism and allied anomalies fall in this class, but also disturbances as illustrated in the following observation.

B. H., a girl, aged 11, suffering from headaches, awakes suddenly from her sleep between 10 and $12 \mathrm{p} . \mathrm{m}$. with violent pains in the region of the stomach, but immediately after falls soundly asleep again. Sometimes this attack may occur in the same night a second time, rarely a third time. The attacks return at rather regular intervals of a fortnight during the past six months. For the past two days she also suffers from pains in the rectum, spontaneous and independent of defecation. Her brother suffers from enuresis nocturna. Inspection and digital examination of the rectum revealed no anomaly, but complete relief of pain resulted immediately. The definite disappearance of the nocturnal attacks of gastralgia and vomiting, for which no organic cause could be detected, on a mere suggestive medication (a few drops of syrup of ipecac) and verbal assurance of cure brings forth into clear view the psychogenic element of this disorder.

Oppenheim has called attention to the relation between certain pains, the so-called hypnalgias and the processes of sleep. A number of his adult patients had suffered from cardialgias or neuralgias that aroused them sooner or later after falling asleep and persisted only a short time after awakening, appearing again as soon as they yielded to the desire to sleep. These pains never began in the waking state. Whatever the explanation may be, in a number of his cases the origin of the disturbance has been, in the view of Oppenheim, probably due to pain hallucinations, that like other sensory illusions are in connection with dreams.

If attacks of fear, ringing in the ears, of pain or paresthesia exacerbate during the night, it may also be due to the patient giving them more attention to his somatic processes or because of the abrogation of the influences of the higher nerve centers.

Hamburger has turned his special attention to sleep disturbances in children, repeatedly observed also by Popper, of an oneirogenic origin, as whining, moaning and complaining, almost exclusively in the sleep, as abdominal pain, or vomiting or coughing attacks without awakening, that yielded readily to simple suggestive therapy (psychotherapy).

Such observations seem strongly to oppose the presumption, no more to be maintained, that pain, cough or vomiting, because occurring during sleep, must necessarily have an organic origin in every instance. Indeed, the sometimes striking curative effect of psychotherapeutic methods, as change of milieu, pedagogical influences, etc., in enuresis nocturna has long been an argument additional to those that likewise proved the correctness of the assumption of its inorganic origin.

\section{TREATMENT}

The psychogenic disturbances, with certain very obstinate exceptions, as a rule are very readily curable. through various means that are essentially psychical. In psychotherapy we attempt to exert our 
influence on the idea, idea-complexes, sensations and emotions of the child; and thereby to act on the functions of the various organs through their close relationship to the psyche. It is superfluous to emphasize the necessity of an exact physical examination, so as not to overlook a somatic disease.

Disturbances of an imitative or induction origin will urgently necessitate the elimination of the inducing person or the removal of the child from his former obnoxious environment; otherwise, when this is impossible, one must not be surprised by recurrences. Yet, even then, permanent disappearance of the symptom in a number of instances were obtained, if the parents carried out the instruction not to make an exhibit of their own affections and by permanent complaining and mention of their own ailments to accentuate the baneful influence on the impressionable child. Czerny proposed for children suffering from pertussis, not to be kept in the same room, since the paroxysm in the one patient will often provoke an attack in the other.

In many cases, the intentional neglect of the child's morbid manifestations will have its important place; especially in irritative conditions, or when previously too great solicitude on the part of the environment, fostered and nurtured as mentioned before, the psychic fixation of the ailment and kept it permanently alive in the mind of the patient. The child may be directly told that his trouble is a minor one, that he exaggerates, or no word may be dropped in his presence, the ailment apparently disregarded and the child observed only without his knowledge. Many a symptom will thus be suppressed in the start. Cessation of the psychogenic complex will spontaneously ensue within a short time, once the child finds no more his sympathetic and interested "public." "The symptoms will gradually die of ennui. The child forgets them, so to speak, altogether" (Bruns).

A pathologic psychic reflex, occurring habitually, may be abolished either by not allowing the provoking "memories" to appear or by linking them up with new displacing associations; thus the unfolding of the former habitual associations-those in the waking state as well as those occurring during sleep-will be frustrated and entirely dislodged. Such memories are especially likely to fail to appear or to be entirely dislodged, if the child's entire life is radically altered, namely, by a complete change of its environment, as for instance by separation from the accustomed surroundings, the removal from the paternal home to a hospital. In other cases the change of the personnel, the introduction of a new attendant or sober-minded nurse will suffice to dislodge the morbid complex.

It is true, an alteration of the milieu in outspoken, hysterical children must be radical and comprise not only a change of place, but in 
addition, also the absence of visitors, especially the separation from family members, the leaving at home of toys and books or other objects that have been in frequent use by the child and therefore are closely connected and interwoven with his manifold associations and morbid complexes of ideas and emotions.

These facts give us the explanation, why we encounter so rarely in hospital practice disorders like somnambulism, pavor nocturnus and other allied oneirogenic disturbances, for evidently the children go to bed with entirely different ideas and thoughts than before, and the previous habitual or stereotypical dream-ideas with their psychomotor reactions do not come into existence.

It is worth recalling to mind the interesting fact, as Friedjung has emphasized, that sleep disorders not of oneirogenic origin, as difficulty in falling asleep, interruption of sleep and wakefulness of children in the night, with restlessness, asking questions and fitful desires and other evil sleep habits may also in most instances be corrected by such simple means as change of the bedroom. A slight change in the arrangements of the life of the child immediately before bedtime will likewise have its effect.

It will often have a most salutary effect for the child to meet and play with healthy and vigorous children; this will more than anything else divert his attention from his physical condition and, indeed, the imitative instinct of the neuropath by being directed into other channels will thus be utilized in bringing the child back to normal habits and tendencies.

Effectual and powerful as the change of milieu may be, circumstances will not always render it expedient, feasible or necessary. We will have to resort to other methods, all aiming likewise at diverting the child from his disturbances and altering favorably his entire conceptions, ideas, deductions and imaginations, conscious as well as subconscious.

Psychotherapy will here have to be addressed directly to the child through simple verbal suggestions, particularly with the support of appropriate apparatuses, auxiliary manipulations, as massage, medication or other supplementary physical means, that impress themselves on the child's mind as wonderful, mysterious or novel, and mask the psychic element of the treatment. The influence of suggestion may reach even the sphere of oneirogenic phenomena and other sleep anomalies, as has been mentioned before.

The certainty, often the rapidity, of a cure may be surprising to the observer, as the mere authoritative word, the emphatic and positive assurance of cure, or, according to the individuality of the patient, 
kind persuasion, encouragement and tact, reward or punishment, will remove the disturbance, the medicine administered serving merely so to speak - as the "visible symbol and token of the invisible force." The authoritative, determined appearance of the physician, his "personality," the firm confidence of the little patient and his belief in the physician and his orders are the conditio sine qua non of a successful treatment of purely psychogenic ailments. Polypragmasy must be avoided. It is the How of administration more important than the What.

It would be preposterous and destructive of the physician's purpose, unwarrantedly to designate these "neurotic" disturbances as hysteria to the parents, who not infrequently resentfully would assail the physician's diagnostic acumen for this terminology, that is so utterly unpopular among laymen.

There is, of course, nothing novel in the principle of these methods, and psychotherapy has been practiced successfully from the beginning of empirical medicine, remaining throughout the ages inseparably connected with our art of healing. However, it was not only then that the disciples of the hippocratean art were unaware of the great therapeutic import of the psychic forces that their words, orders and prescriptions carried; that they scarcely suspected the paramount rôle psychic elements play in the composite aspect of the clinical pictures. They hardly could realize the true and real nature of the curative agency and principle. Wherever an adequate appreciation and appraisal of the psychic moments is still wanting, self-deception is likely to follow and without criticism to attribute too much merit to pharmaceutical preparations; this will lead to a regrettable neglect of a therapeutic principle that in systematic and rational application is bound to yield excellent results, far better than in the hand of the merely intuitive user among our profession, not to speak of the commercial faith healers, Christian scientists and other false prophets without any medical training, but with much pretension and arrogance.

I often found it good procedure to hold out and reiterate the prospect of cure not directly to the child, but in his presence to his mother, or in my dispensary work, in addressing the students, augmenting thereby the suggestive effect by the prestige and authoritativeness of the teacher.

By force of verbal suggestion, aided by pharmacodynamically often indifferent medicines, I succeeded in perhaps every case in abolishing the disorders, as tremor, pains, arthralgias, nervous dyspneas, palpitation of the heart, nervous vomiting, limping, etc. Naturally, one must be rather sure of being master of the situation; otherwise, if 
the first psychic blow falls very short of its goal and the prediction fails of early realization, the child's trust and faith in the curative force is considerably shaken and the probabilities of a cure by the same physician reduced. In cases of palsy it is often important to prove to the child that he can use his limbs much better than he supposed.

As a last resort - if not used at the first - a more powerful means, impressive through a certain degree of unpleasantness or even painfulness, will find its proper place; as for instance, the faradic current that even in tics, an usually obstinate affection, has proved to be of great curative value. Also cold baths, subcutaneous injections, bitter or disagreeable medicines and other measures of a disagreeable character come here into consideration.

In many instances a method that takes the patient by surprise by its sudden, unexpected application, as for instance, the faradic brush, cold douche, forcible extension of a contracted joint, especially in a changed environment, in the absence of the parents, be it only the office of the physician, finds its indication, particularly in cases of paralysis, contracture, aphonia, etc., or when the intentional neglect failed to create improvement. A strong faradic brush is, in fact, the most persuasive master in such cases. Before the mind of the child, confronting a strange personality and surrounded by a new environment, has had time to find its orientation, or before doubt and criticism could arise, the child overwhelmed at once must have surrendered and the result be obtained. The failure to subjugate the child under the force of suggestion will disclose to him "that he has not yet found his master," and the chances of cure are much diminished. According to the individuality of the child, a peremptory command, if necessary a severe word, may suffice. "The physician lifts up the paralyzed arm and letting it loose, briefly commands : Now keep the arm up" (Bruns).

It will most often be better and safer, instead of using the surprise method, to proceed gradually and slowly; we thereby aim not at the immediate and total, but only at the partial removal of the symptom by our verbal suggestion and encouragement, until within a few days the complete elimination is obtained. Especially may this method be necessary in cases of more severe disturbances in older children, in whom according to the patient's personality the attempt at a complete cure by one stroke might arouse the critical doubt, especially when manifold futile therapeutic measures have already been employed. Of course under all circumstances, any countersuggestive influence, as for instance, the expression of doubt as to the curability by surrounding persons, a careless remark or the aspect of a sick neuropathic 
individual must be avoided. It will be left to the physician's experience, ingenuity, discretion and sagacity to decide the kind of procedure in the individual case.

\section{HISTORY OF A CASE OF ASTASIA AND ABASIA}

G. K., a girl, aged 11 years, eight days before admission to the Cook County Hospital while retiring felt suddenly that her left leg became weak and gave way and she fell over into her bed. Since then she was bedridden and unable to stand or walk without assistance, dropping forthwith to the floor if not held up. At my first examination, the child's ability while in bed to move the lower extremities with energy, was deliberately dwelt on and suggestively emphasized in the presence of other physicians, as a very good sign of a speedy recovery. She took this as a proof that "her limbs were much better than she had thought." The next day she was able to walk a few steps unsupported, and with encouragement she became, on the third day, able to participate in the plays and running games of the children. No medication.

Psychotherapy is successfully applicable not only in purely and entirely psychogenic diseases, but also for the removal of psychogenic complexes that aggravate or complicate acute and chronic diseases of organic nature, and for the removal of psychogenic residues. They may be very insignificant or in other instances, by their intensity and duration, may far surpass the originally organic symptom, as for instance, the hysterical painful contractures of joints, or abasia and astasia. The recognition of the psychogenic nature of a disturbance by suggesting a possible neuropathic constitution will lead to a therapy that considers the entire individual and treats not merely the symptom, but the patient, employing in addition to the special treatment general measures which have an invigorating effect on the nervous system. It will lead to a pedagogical consideration of the problem and the employment of educational methods that aim at "psychic hardening." The child, too often spoiled, must learn to control his emotions and, subordinating himself to the educator, acquire the inhibitory influences of a well directed will power.

\section{COMMENT}

Psychotherapy in childhood particularly gains additional importance in consideration of its applicability as a differential-diagnostic medium in the distinction between neurotico-functional and organic disturbances. Its use, cum grano salis, with the point in view of confirming our diagnostic presumption, cannot be overestimated, and its instrumentality is ever emphasized in my teaching at the dispensary. An abundant material for the demonstration of such neurotic cases and their treatment aided substantially in bearing out these claims. A purely psychogenic symptom or residue of an organic disease will with a great degree of certainty be pronouncedly influenced, mostly very soon 
cured, or the psychogenic complication from the organic ailment so to speak subtracted, and thus our diagnostic endeavor aided. The diagnostic significance of a striking positive result in an obscure and questionable case, the diagnosis ex juvantibus rivals the differential diagnostic value of an effective mercurial cure in lesions suspicious of syphilis.

4557 Broadway.

\section{BIBLIOGRAPHY}

Hamburger: Monatsch. f. Kinderh., 1914, 13, 23.

Hecker: The Epidemics of the Middle Ages, 1846. (Translated from the German.)

Ibrahim: Neurol. Centralbl., 1911, p. 715.

Krasnogorski, N.: Jahrb. f. Kinderh., 1909, 69, 1.

Lesage and Collin: Gaz. d. hôp., 1911, p. 96.

Strauch, A.: Disorders in Children by Imitation and Induction, Med. Rec., New York, 1914, 85, 95. 